http://www.jfas.info

\title{
ESTABLISHING RELIABILITY OF PERFORMANCE INDICATOR OF SEPAK TAKRAW USING NOTATIONAL ANALYSIS
}

\author{
N. A. Kosni ${ }^{1,2}$, M. R. Abdullah ${ }^{1,2,}$, H. Juahir ${ }^{1}$, A. B. H. M. Maliki ${ }^{2}$ and R. M. Musa ${ }^{2}$ \\ ${ }^{1}$ East Coast Environmental Research Institute, University of Sultan Zainal Abidin, Gong \\ Badak Campus, 21300 Kuala Terengganu, Terengganu, Malaysia \\ ${ }^{2}$ Faculty of Applied Social Sciences, University of Sultan Zainal Abidin, Gong Badak \\ Campus, 21300 Kuala Terengganu, Terengganu, Malaysia
}

Published online: 08 August 2017

\begin{abstract}
The aim of this study is to establish the necessary reliability in the notational analysis of sepak takraw. Two performance analysts were recruited to help in the collection of the data. The performances were analyzed based on the main performance indicators relevant to the demand of the game. Cronbach's alpha and Cohen's kappa reliability testing was implemented to test the reliability of the information collected. The results for reliability shows $[\alpha=0.91$ and $\mathrm{K}=0.89(0.092,95 \%), \mathrm{p}<0.05]$ respectively, which confirmed the reliability of the information collected from the analysis. This paper has revealed that reliability in the notational analysis could be achieved. Performance analysts should ensure the reliability of their analysis before being relayed to the coach.
\end{abstract}

Keywords: sepak takraw; performance indicators; notational analysis; reliability.

Author Correspondence, e-mail: razali896@yahoo.com

doi: http://dx.doi.org/10.4314/jfas.v9i2s.1 


\section{INTRODUCTION}

Notational analysis is a division of sports and exercise science that measures the real performance of an athlete as opposed to views or self-report by the athlete, coach or an observer [1]. Notational analysis is primarily utilized in several sports to assist coaches acquire an objective data that can be used to give feedback on performance [2]. Providing feedback on performance in sports is reported to play a significant role in improving the overall performance of athletes [3-4]. The advantages of notational analysis in sports cannot be overemphasized. For example, the data from the notational analysis can be used to determine the rate of performance of the athletes and also use the information generated from the analysis in designing a training program aimed at addressing the athletes weakness and improving their strength which further makes the coaching process more scientific and objective [5].

Reliability is the extent to which measurement procedure can be relied upon to produce consistent results upon repeated application [6]. Reliability is the degree to which a test measures consistently what it is supposed to measure. In other words, reliability is the level to which measures are free from blunder and along these lines yield reliable results (i.e. the consistency of an estimation technique) [7]. In the event that an estimation gadget or method reliably does out the same score to people or articles with equivalent values, the instrument is viewed as reliable. However, reliability include the measurement ability of an instrument to purposely evaluate what it is intended to evaluate as well as the consistency or reproducibility of test scores, i.e., the extent to which one can generally expect consistent deviation scores of people crosswise over testing circumstances on the same, or parallel, testing instruments [8-9].

Sports performance information has been measured and gathered via the use of various methods including different measurement devices in the area of notational analysis of sports and games [10], it is essential consequently to investigate the reliability tests utilized for such information. Several notational analysis systems are being utilized in the notational analysis of sports to give coaches and players information on their performance [11]. However, most performance analysts neglect to consider or seldom establish the reliability of their analysis 
tool assuming that the presence of the clear operational definition of performance parameters ensures the reliability of the testing instrument [12]. It is vital to note that the presence of precise operational definitions does not ensure great reliability nor does their deficiency ensure poor reliability. Establishing reliability of any notational analysis application is fundamental in order for the data to be trustworthy. Consequently, any estimation of reliability measurement thought to be adequate needs to be legitimized. Limited reliability can bring variability into data that diminishes the possibility of discovering a critical distinction. Hence, the purpose of this paper is to establish the fundamental reliability in notational analysis of sepak takraw.

\section{METHODOLOGY}

\subsection{Participants}

In the present study, two performance analysts were recruited from sport science post-graduate students of Universiti Sultan Zainal Abidin, Terengganu, Malaysia. One of the sepak takraw youth athlete team (Tunku Mahkota Ismail Sport School) competing in National Sepak Takraw Circuit League, where involved in this study.

\subsection{Samples}

Video material was taken at the national youth circuit league 2016. The match video was filmed with one camera, which was located beside the court. For a good viewpoint on the court, the officials, such as referees and linesmen, the videos were captured from a high spot. Strict placement and elevation of the camera was dependent on the hall setting and space in the hall was limited. Distance from the sideline was about 15 meters and height above the court was about 5 meters.

\subsection{Data Collection Procedure}

A complete match was recorded using video handy camera during the competition. The performance analysts were asked to notate the performance of the player in video role-play based on certain performance indicators relevant to the demand for the game. The performance analysts were trained to disseminate themselves with the performance indicators. The performance indicators were Servicing, Passing, Break-ball, Blocking, Spiking and Fault. 
Hand notational analysis with three sets of a game was recorded so can be applied on this research for further analysis. Furthermore, notational analysis was notated using android base application (Statwatch) and its procedure adopted from the prior study [11]. Each analyst is given a form and a pen to notate all the action performed by the team.

\subsection{Performance Indicators}

Parameters to indicate the performance was listed and the description of each parameter were stated. Twenty two actions of parameter included in this study, explicitly; service ace (SA), service effective (SE), service weak (SW), service net (SN), service out (SO), break ball success $(\mathrm{BrS})$, break ball weak $(\mathrm{BrW})$, break ball fail $(\mathrm{BrF})$, passing success $(\mathrm{PS})$, passing weak (PW), passing fail (PF), passing desperate (PD), blocking success (BS), blocking weak (BW), blocking fail (BF), killing ace (KA), killing effective (KE), killing weak (KW), killing net $(\mathrm{KN})$, killing out $(\mathrm{KO})$, foul $(\mathrm{F})$ and opponent mistake $(\mathrm{OM})$. Before run the notational analysis, an operational of each indicator was demonstrated to the performance analysts using video of the sepak takraw match to ensure the analysts understood the definition of the indicators [13].

\subsection{Statistical Analysis}

To test the consistency of the two performance analysts, a Cronbach's Alpha statistical coefficient was employed [14] to be appropriate when a consistency is to be measured based on certain parameters [20-24]. To further ensure that the performance analyst agreed beyond chance on actions performs by the player, we randomly picked two performance analysts and instructed them to notate the performance of the player based on the performance indicators and Cohen's Kappa inter-tester reliability testing was used to determine whether the performance analysts agreed unanimously on the actions performed by the player. All the data were analyzed using SPSS version 20 for windows at a confidence level of $p \leq 0.05$ [25-30].

\section{RESULTS AND DISCUSSION}

Table 1 shows the descriptive statistics of Cronbach's alpha conducted by two performance analysts. The mean and the standard deviation number of the variables are disclosed. 
Table 1. The descriptive statistics of performance indicator by two analysts

\begin{tabular}{ccccc}
\hline Performance Indicator & PA*A & PA*B & Mean & SD \\
\hline Service Ace (SA) & 3 & 3 & 3.00 & 0.00 \\
Service Effective (SE) & 16 & 15 & 15.50 & 0.71 \\
Service Weak (SW) & 14 & 14 & 14.00 & 0.00 \\
Service Net (SN) & 17 & 17 & 17.00 & 0.00 \\
Service Out (SO) & 3 & 3 & 3.00 & 0.00 \\
Break ball success (BrS) & 24 & 24 & 24.00 & 0.00 \\
Break ball Weak (BrW) & 9 & 9 & 9.00 & 0.00 \\
Break ball fail (BrF) & 13 & 12 & 12.50 & 0.71 \\
Passing Success (PS) & 26 & 26 & 26.00 & 0.00 \\
Passing Weak (PW) & 6 & 5 & 5.50 & 0.71 \\
Passing Fail (PF) & 1 & 1 & 1.00 & 0.00 \\
Passing Desperate (PD) & 1 & 1 & 1.00 & 0.00 \\
Blocking Success (BA) & 2 & 2 & 2.00 & 0.00 \\
Blocking Weak (BW) & 2 & 2 & 2.00 & 0.00 \\
Blocking Fail (BF) & 7 & 8 & 7.50 & 0.71 \\
Killing Ace (KA) & 7 & 7 & 7.00 & 0.00 \\
Killing Effective (KE) & 15 & 15 & 15.00 & 0.00 \\
Killing Weak (KW) & 3 & 3 & 3.00 & 0.00 \\
Killing Net (KN) & 5 & 5 & 5.00 & 0.00 \\
Killing Out (KO) & 2 & 2 & 2.00 & 0.00 \\
Foul (F) & 0 & 0 & 0.00 & 0.00 \\
\hline
\end{tabular}

Table 2 shows the Cronbach's alpha coefficient and the number of the participants. The Cronbach's alpha coefficient indicates 0.998 , which revealed a high consistency among the performance analysts in their analysis of the performance indicator. 
Table 2. Cronbach's alpha coefficient and the number of the participants

\begin{tabular}{cc}
\hline Cronbach's Alpha & N of Items \\
\hline 0.998 & 2 \\
\hline
\end{tabular}

Table 3 reveals the descriptive statistics for the Cohen's Kappa statistical agreement between the two analysts (Analyst A and Analyst B). The number of variables for the analysis as well as the total percent is presented. No missing value is stated.

Table 3. Descriptive statistics for Cohen's Kappa statistical agreement

\begin{tabular}{ccccccr}
\hline Participants & \multicolumn{4}{c}{ Cases } \\
& \multicolumn{2}{c}{ Valid } & \multicolumn{2}{c}{ Missing } & \multicolumn{2}{c}{ Total } \\
& N & Percent & N & Percent & N & Percent \\
\hline Analyst1 * Analyst2 & 22 & 100 & 0 & 0 & 22 & 100 \\
\hline
\end{tabular}

Table 4 shows the inferential statistics of the analysis for the Cohen's Kappa's measure of agreement. The result shows $\mathrm{K}=0.76, \mathrm{p}<0.001$, which indicated that the agreements among the performance analysts was beyond any chance. Therefore, they actually agreed on almost the same actions performed by the player.

Table 4. Inferential statistics for Cohen's Kappa between the two analysts

\begin{tabular}{cccccc}
\hline & & Value & Asymp. & Approx. & Approx. \\
& & & Std. & $\mathbf{T}^{\mathbf{b}}$ & Sig. \\
& & & Error $^{\mathbf{a}}$ & & \\
\hline Interval by Interval & Pearson's R & 0.997 & 0.002 & 56.579 & $0.000^{\mathrm{c}}$ \\
Ordinal by Ordinal & Spearman & 0.999 & 0.001 & 93.728 & $0.000^{\mathrm{c}}$ \\
& Correlation & & & & \\
Measure of Agreement & Kappa & 0.755 & 0.093 & 13.119 & 0.000 \\
N of Valid Cases & 22 & & & \\
\hline
\end{tabular}

The purpose of the current study is to establish the reliability of performance indicator on sepak takraw game by using Statwatch application android based. The performance indicator of the sepak takraw match was observed relevant to the demand of game itself. Based on the result of Cronbach Alpha (see Table 2) and Cohen Kappa (see Table 4) show the confirmation 
of the reliability of the information collected by the performance analyze, and also the agreement of the operational of the performance indicators in sepak takraw game $(\alpha=0.91$ and $\mathrm{K}=0.89(0.092,95 \%), \mathrm{p}<0.05)$ respectively.

Reliability test purposely conducted in this study is to determine the consistency of the measurement between the performances analysts on sepak takraw game, which Cronbach's Alpha coefficient (0.91) is confirmed with a high level of measurement consistency among the analysts. The value of Cronbach alpha coefficient equals or above 0.90 indicates a perfect and excellent in term of consistency across all variables [14]. Similarly, prior study reported that when the value of Cronbach alpha coefficient greater than 0.90 obtained from the instrument with a stable and consistent feedback, it is said to be reliable [15]. Furthermore, this finding describe that there was an excellent evaluation feedback because of the consistency in the measurement of the performance indicator of sepak takraw game by the analysts with a reflection of a high internal reliability of the information gathered.

Even though all the information gathered by the analyst projected a reliable result, but this test did not explained the agreement of the measurement among the analysts [16] based on the action in the sepak takraw game. To further solidify the reliability of the information gathered between the analysts, Cohen Kappa test was run to investigate if there was an agreement between the two analysts. Based on the result (see Table 4) it is shown that there was an agreement between the two analysts $(K=0.76(0.093,95 \%), \mathrm{p}<0.05)$. Furthermore, this indicated that the agreement between two performance analysts was almost perfect and this agreement of operational definition in performance indicators are beyond chance on almost the same actions performed by the action of the video (see Table 1). Similarly, prior research stated that if the value of the Cohen's Kappa coefficient ranges from 0.70 and above indicates an agreement and was beyond any chance [17-18]. Nevertheless, Table 1 shows the tabulation of the agreement between two performance analysts on all performance indicators that supported current research that the two analysts agreed almost on all indicators. Only a few indicators which is service effective $(\mathrm{SE})$, break ball effective $(\mathrm{BrF})$, passing weak $(\mathrm{PW})$, blocking fail (BF) and opponent mistake (OM) shows discrepancy but the case is not too serious because of the standard deviation shows small values. Moreover, discrepancy of 
agreement normally exist between two evaluators since it is hard for them to perfectly agreed or disagree (100\%) in a genuine cases (e.g. different level of expertise and skills). If the inconsistency is not a major or critical case, the agreement between the evaluators considered to be above chance [18-19]. Thus, it is tempting to conclude that the agreement of the operational measurement on performance indicators between two performance analysts was beyond chance.

\section{CONCLUSION}

The significance of reliability in notational analysis can never be over emphasized. Nevertheless, for any information given to the coach or player to be relied upon, needs to be reliable. This study revealed that reliability in the notational analysis of sepak takraw could be achieved. It further discovered that the information that could be obtained via the analysis would be more accurate and reliable for the coach and the players to have feedback on their performance. Performance analysts should therefore ensure the reliability of any information that could be generated from their notational analysis before transmitting it to the coach or athlete.

\section{ACKNOWLEDGEMENTS}

The authors would like to thank the East Coast Environmental Research Institute, University of Sultan Zainal Abidin for financial support and Tunku Mahkota Ismail Sport School for authorizes to record and analyze the athlete's competition analysis.

\section{REFERENCES}

[1] O'Donoghue P. Research methods for sports performance analysis. New York: Routledge, 2009

[2] Travassos B, Araújo D, Correia V, Esteves P. Eco-dynamics approach to the study of team sports performance. Open Sports Sciences Journal, 2010, 3:56-57

[3] Hook C, Hughes M D. Patterns of play leading to shots in Euro 2000. In World conference of notational analysis of sport, 2001, pp. 295-302 
[4] Sarmento H, Marcelino R, Anguera M T, Campaniço J, Matos N, Leitão J C. Match analysis in football: A systematic review. Journal of Sports Sciences, 2014, 25(9):969-974

[5] Carling C., Reilly T., Williams A. Performance assessment for field sports. New York: Routledge, 2009

[6] Weiner J. Measurement: Reliability and validity measures. 2007, http://ocw.jhsph.edu/courses/hsre/pdfs/hsre_lect7_weiner.pdf

[7] Sechrest L. Reliability and validity. In A. S. Bellack, \& M. Hersen (Eds.), Research methods in clinical psychology. New York: Pergamon Press, 1984, pp. 24-54

[8] Thanasegaran G. Reliability and validity issues in research. Integration and Dissemination, $2009,4: 35-40$

[9] Lames M, McGarry T. On the search for reliable performance indicators in game sports. International Journal of Performance Analysis in Sport, 2007, 7(1):62-79

[10] Choi H, O'Donoghue P, Hughes M. An investigation of inter-operator reliability tests for real-time analysis system. International Journal of Performance Analysis in Sport, 2007, $7(1): 49-61$

[11] Abdullah M R, Musa R M, Suppiah P, Bahrin M N, Wong T K K, Zainal E M C K. Comparative analysis on the user-friendliness between computer and tablet application in the performance analysis of soccer. International Journal of Science and Technology, 2015, $4(7): 368-372$

[12] O'Donoghue P. Reliability issues in performance analysis. International Journal of Performance Analysis in Sport, 2007, 7(1):35-48

[13] Abdullah M R, Musa R M, Suppiah P, Bahrin M N, Wong T K K, Zainal E M C K. Performance analysis in soccer: Using tablet application. In MOHE'15, 2014

[14] Revelle W, Zinbarg R. Coefficients alpha, beta, omega and the glb: Comments on Sijtsma. Psychometrika, 2009, 74(1):145-154

[15] Drost E A. Validity and reliability in social science research. Education Research and Perspectives, 2011, 38(1):105-124

[16] Brown E, O'Donoghue P. Relating reliability to analytical goals in performance analysis. International Journal of Performance Analysis in Sport, 2007, 7(1):28-34 
[17] Ferrari P, Friedenreich C, Matthews C. E. The role of measurement error in estimating levels of physical activity. American journal of epidemiology, 2007, 166(7):832-840

[18] Altman D G. Some common problems in medical research. In D. G. Altman (Ed.), Practical statistics for medical research. London: Chapman and Hall, 1990

[19] James N, Taylor J, Stanley S. Reliability procedures for categorical data in performance analysis. International Journal of Performance Analysis in Sport, 2007, 7(1):1-11

[20] Al-Odaini N A, Zakaria M P, Zali M A, Juahir H, Yaziz M I, Surif S. Application of chemometrics in understanding the spatial distribution of human pharmaceuticals in surface water. Environmental Monitoring and Assessment, 2012, 184(11):6735-6748

[21] Juahir H, Zain S M, Aris A Z, Yusof M K, Samah M A, Mokhtar M. Hydrological trend analysis due to land use changes at Langat River Basin. Environment Asia, 2010, 3:20-31

[22] Mun'im M H N, Latif M T, Othman M, Dominick D, Mohamad N, Juahir H, Tahir N M. Composition of selected heavy metals in road dust from Kuala Lumpur City Centre. Environmental Earth Sciences, 2014, 72(3):849-859

[23] Aris A Z, Abdullah M H, Praveena S M, Yusoff M K, Juahir H. Extenuation of saline solutes in shallow aquifer of a small tropical island: A case study of Manukan Island, North Borneo. Environment Asia. 2010, 3(Special Issue):84-92

[24] Toriman M E, Gasim M B, Yusop Z, Shahid I, Mastura S S, Abdullah P, Jaafar M, Aziz N A, Kamarudin M K, Jaafar O, Karim O. Use of 137 Cs activity to investigate sediment movement and transport modeling in river coastal environment. American Journal of Environmental Sciences, 2012, 8(4):417-423

[25] Abdullah M R, Maliki A B H M, Musa R M, Kosni N A, Juahir H, Mohamed S B. Identification and comparative analysis of essential performance indicators in two levels of soccer expertise. International Journal on Advanced Science, Engineering and Information Technology. 2017, 7(1):305-314

[26] Abdullah M R, Maliki A B H M, Musa R M, Kosni N A, Juahir H, Haque M. Multi-hierarchical pattern recognition of athlete's relative performance as a criterion for predicting potential athletes. Journal of Young Pharmacists, 2016, 8(4):463-470

[27] Abdullah M R, Eswaramoorthi V, Musa R M, Maliki A B H M, Kosni N A, Haque M. 
The effectiveness of aerobic exercises at difference intensities of managing blood pressure in essential hypertensive information technology officers. Journal of Young Pharmacists, 2016, $8(4): 483-486$

[28] Abdullah M R, Musa R M, Maliki A B H M, Kosni N A, Suppiah P K. Development of tablet application based notational analysis system and the establishment of its reliability in soccer. Journal of Physical Education and Sport, 2016, 16(3):951-956

[29] Musa R M, Abdullah M R, Maliki A B H M, Kosni N A, Haque M. The application of principal components analysis to recognize essential physical fitness components among youth development archers of Terengganu, Malaysia. Indian Journal of Science and Technology, 2016, 9(44):1-6

[30] Abdullah M R, Kosni N A, Eswaramoorthi V, Maliki A B H M, Musa R M. Reliability of test of performance strategies-competition scale (TOPS-CS) among youth athletes: A preliminary study in Malaysia. Man in India, 2016, 96(12):5199-5207

\section{How to cite this article:}

Kosni N A, Abdullah M R, Juahir H, Maliki A B H M, Musa R M. Establishing reliability of performance indicator of sepak takraw using notational analysis. J. Fundam. Appl. Sci., 2017, 9(2S), $1-11$. 